\title{
Climate events and the role of adaptive capacity for (im-) mobility
}

\author{
Vally Koubi ${ }^{1}$ - Lena Schaffer ${ }^{2} \cdot$ Gabriele Spilker $^{3} \cdot$ Tobias Böhmelt $^{4}$
}

Accepted: 7 December 2021 / Published online: 8 January 2022

(c) The Author(s) 2022

\begin{abstract}
The study examines the relationship between sudden- and gradual-onset climate events and migration, hypothesizing that this relationship is mediated by the adaptive capacity of affected individuals. We use survey data from regions of Cambodia, Nicaragua, Peru, Uganda, and Vietnam that were affected by both types of events with representative samples of non-migrant residents and referral samples of migrants. Although some patterns are country-specific, the general findings indicate that less educated and lower-income people are less likely to migrate after exposure to sudden-onset climate events compared to their counterparts with higher levels of education and economic resources. These results caution against sweeping predictions that future climate-related events will be accompanied by widespread migration.
\end{abstract}

Keywords Climate change $\cdot$ Climate events $\cdot$ Adaptive capacity $\cdot(\mathrm{Im}$-)mobility

Vally Koubi

koubi@ir.gess.ethz.ch

Lena Schaffer

lena.schaffer@unilu.ch

Gabriele Spilker

gabriele.spilker@uni-konstanz.de

1 Center for Comparative and International Studies (CIS), Department of Economics, ETH Zurich, University of Bern, IFW C 43.2, Haldeneggsteig 4, Zürich 8092, Switzerland

2 Faculty of Humanities and Social Sciences, University of Luzern, Frohburgstrasse 3, Luzern 6002, Switzerland

3 Department of Politics and Public Administration, University of Konstanz, Konstanz 78457, Germany

4 Department of Government, University of Essex, Wivenhoe Park, Colchester CO4 3SQ, UK 


\section{Introduction}

Global warming will raise the frequency and intensity of extreme weather and climate events such as cyclones, floods, wildfires, or droughts (IPCC SR $1.5^{\circ} \mathrm{C} 2018$ ). In turn, these climate events may lead to more migration flows especially of vulnerable populations (Rigaud et al., 2018). There is sufficient evidence for the claim that climate-related events make it more likely that people will migrate, mostly within their own states (e.g., Rigaud et al., 2018; Afifi et al., 2016; Foresight, 2011). For example, under a "business-as-usual scenario," which is characterized by high greenhouse gas emissions and unequal development, the World Bank's "Groundswell" report predicts more than 143 million internal migrants due to droughts in Sub-Saharan Africa, South Asia, and Latin America alone by 2050 (Rigaud et al., 2018). And Missirian and Schlenker (2017) highlight that the number of "environmental refugees" seeking asylum in the EU could increase by nearly $200 \%$ by the end of 2100.

However, a significant amount of variation persists in the migration patterns of people affected by the same climate event (e.g., Black et al., 2011, 2013; Field et al., 2012; Cattaneo et al., 2019; Bohra-Mishra et al., 2014, 2017; Thiede \& Gray, 2017; Gray \& Wise, 2016; Thiede et al., 2016; Koubi et al., 2016a, 2016b; Williams \& Gray, 2020). While there is some evidence that migration results from a dynamic range of interactions between climate events and individual or household-level characteristics such as wealth or education (Bohra-Mishra et al., 2017; Logan et al., 2016; Warner \& Afifi, 2014; Warner et al., 2012), the corresponding findings stem mostly from single-country analyses. For instance, while environmental migrants in Peru are predominantly younger males, migrants are equally distributed across gender categories in Vietnam (Warner et al., 2012). Moreover, evidence from the USA over the past three decades points toward a "segmented withdrawal" of populations after hurricane damage, meaning that economically advantaged groups leave, while vulnerable populations do not have the resources to do so (Logan et al., 2016). The research on the individual and household-level factors, which condition the impact of climate events on migration thus remains limited (e.g., Williams \& Gray, 2020; Hunter, 2018; BohraMishra et al., 2017; Baez et al., 2017; Thiede \& Gray, 2017; Thiede et al., 2016; Warner and al., 2012). Hence, there is need for more work to identify and better understand what specific factors shape individuals' decisions to migrate in the presence of climatic changes - and especially under what conditions (Cattaneo et al., 2019; Hunter, 2018; Williams \& Gray, 2020; Zickgraf, 2018).

We contribute to this literature by studying how individual and household characteristics condition the effect of climate change on (im-)mobility (Hunter, 2018; McLeman \& Smit, 2006; Wiegel et al., 2019). While migration clearly depends on and is driven by the particular type of a climate event (Cattaneo et al., 2019; Koubi et al., 2016a; Spilker et al., 2020), the impact of the latter is likely contingent on characteristics that form individuals' ability to cope with and adapt to climate change (Black et al., 2011; Williams \& Gray, 2020; Zickgraf, 2018). This focus is not only relevant for the study of climate-induced migration as an adaptation 
strategy (Gemenne \& Blocher, 2017), but also because it helps explaining why some people are immobile and do not migrate in the presence of climatic changes, while others do (Carling, 2002; Carling \& Schewel, 2018; Zickgraf, 2018). The Foresight (2011) report introduced here the concept of "trapped populations" to describe those who are vulnerable to climatic changes but lack the means to move (see also Black \& Collyer, 2014; Ayeb-Karlsson et al., 2018).

We develop arguments on how different types of climate events and individual/ household characteristics interact in influencing intra-state migration. While most studies center on one specific climate event (e.g., drought) or a single country, we focus on both gradual/long-term events, e.g., droughts or salinization, and sudden/ short-term events, e.g., storms or floods, and contend that individuals have varying capacities to adapt, which facilitate mobility in some cases, but not in others. We empirically test our argument with survey data from five developing countries: Vietnam, Cambodia, Uganda, Nicaragua, and Peru. The data include both individuals who migrated and those who stayed after experiencing specific climate events. Furthermore, while most existing studies use actual climatic data in the form of, e.g., temperature and precipitation (Baez et al., 2017; Bohra-Mishra et al., 2017; Gray \& Wise, 2016), an important advantage of our data is that we integrate individual perceptions of climate events with other migration-relevant determinants at the individual and household levels to provide a comprehensive picture of the determinants of (non-)migration (Adger et al., 2015; Hunter et al., 2015; McLeman, 2014).

Our results suggest that migration depends on both the type of the climate event individuals experience as well as their adaptive capacity. In particular, less-educated and poor individuals are less likely to migrate, and often are immobile in the presence of sudden/short-term climate events. This finding corroborates one of the central messages of the Foresight (2011) report, namely that people lacking resources to leave become immobile in areas of high vulnerability to climatic changes (see also Black et al., 2013). This research informs the discussion about climate-change induced migration. From a policy perspective, we caution against predictions that climate-related events will be accompanied by widespread migration in the future.

\section{Mobility and immobility in response to climate events}

Climate change shapes individuals' migration considerations (e.g., Adger et al., 2018; Cattaneo et al., 2019; Hoffmann et al., 2020). In the following, we build on this existing literature, which notes that a better understanding of environmental influences for migration dynamics necessitates the examination of how and why people are vulnerable to climate change, as well as the different strategies individuals develop to adapt to environmental stress (Piguet et al., 2011: 2). We, consequently, argue that a useful way to gain additional insights into the relationship between climate change and migration is to focus on the interaction between (1) the characteristics of a climate event that make adaption more or less likely and (2) an individual's abilities to adapt to the impact of the particular climate event (Field et al., 2012; Piguet et al., 2011; McLeman \& Smit, 2006). More precisely, we focus on sudden/short-term and gradual/long-term climate events (Field et al., 2012: 117), 


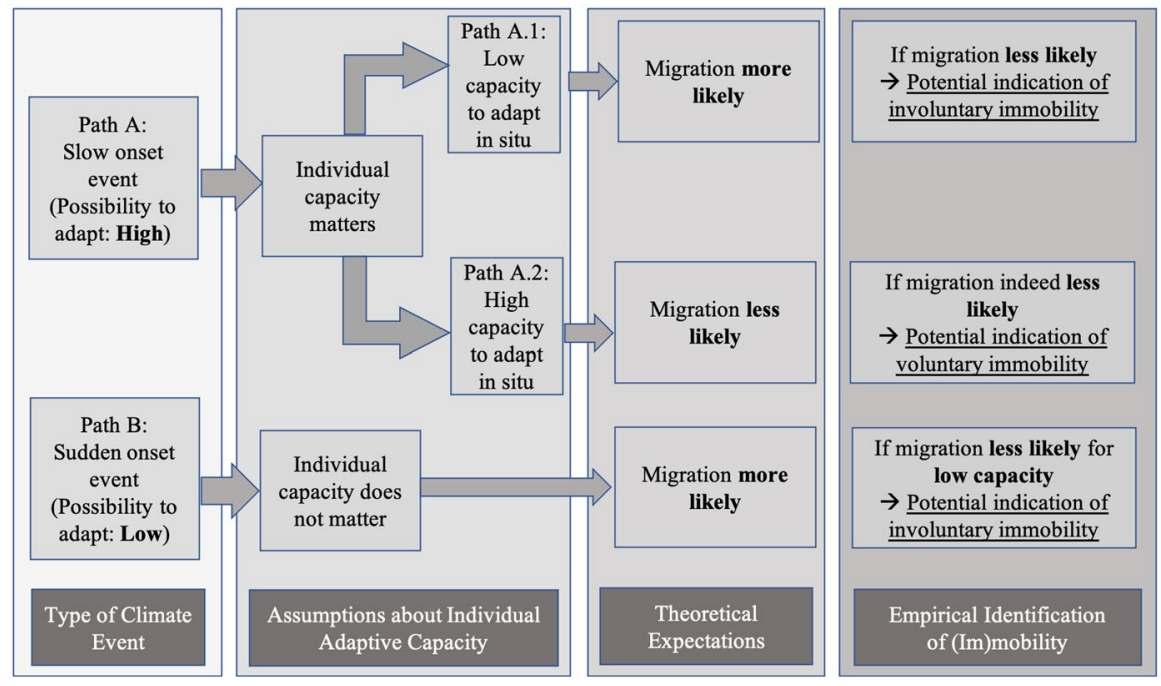

Fig. 1 Overview of theoretical arguments

which differ in the extent to which in situ adaptation is possible. To assess an individual's adaptive capacity, we concentrate on her human and financial capital. From this interplay of climate events and individual adaptive capacity, we expect to find out more about the drivers of environmental (im-)mobility.

Figure 1 provides an overview of our theory and the corresponding empirical expectations, which we discuss in detail below. This graph depicts how the likelihood of migration should change depending on the characteristics of a climate event (left panel) and, secondly, an individual's adaptive capacity (two middle panels). The figure starts on the left-hand side with the distinction between sudden/shortterm and gradual/long-term climate events that, as we argue, are associated with a higher (slow-onset event) or lower (sudden-onset event) in situ adaptation probability. The second and third panels then show how we conceive of the impact of individual capacity to adapt to different climate events. The last panel on the right-hand side summarizes the implications of our argument and under what conditions we may treat people who have not migrated as "involuntarily immobile."

\section{Types of climate events}

We base our theory on the argument that different types of climate events affect the decision to migrate in diverse ways (Cattaneo et al., 2019; Koubi et al., 2016a, b, c; McLeman, 2014). We distinguish between sudden/short-term and gradual/long-term climate events to this end (see also Field et al., 2012). Sudden/short-term climate events, e.g., floods and storms, tend to have severe, immediate impacts on the wellbeing of individuals by inflicting injuries and casualties as well as causing economic disruption and food insecurity (Wallemacq et al., 2018). In such cases, "people must flee from a rapid-onset environmental event to save their lives" (Warner, 2010: 405). 
Here, individuals can hardly adapt in situ and, hence, the costs of migration as an adaptation strategy should be lower than the ones associated with staying where they are. As a result, the "aspiration to migrate" 1 is high and, indeed, existing literature shows that sudden/short-term climate events are linked to a higher probability of migration (Cattaneo et al., 2019; Koubi et al., 2016a, 2016b).

Gradual/long-term climate events, e.g., droughts or water/soil salinity, are usually not regarded as sufficiently extreme to trigger migration, since they have less of an immediate impact on individuals (Adams, 2016; Farbotko et al., 2018). People are more willing (and able) to adjust their productive strategies in the presence of gradual climate events (e.g., Al-Amin et al., 2019; Jamero et al., 2017; Soglo \& Nonvide, 2019) and, therefore, adaptation in situ is more likely (Field et al., 2012: 44). When subscribing to the (anticipated) effectiveness of adaptation strategies, in general, gradual/long-term climate events are likely to have a weaker effect on migration compared to sudden/short-term events. In turn, slow-onset events are often associated with immobility (Cattaneo et al., 2019; Koubi et al., 2016a, 2016b).

However, not everyone suffers equally from a particular climate event, and individuals' differentiated vulnerability to climate events thus has diverse effects on their (im-)mobility. The level of vulnerability and, hence, whether it triggers mobility is linked to how severely people perceive events to affect their lives (Carling \& Schewel, 2018; Zickgraf, 2018). ${ }^{2}$ In line with other studies (e.g., Hunter et al., 2015; Koubi et al., 2016a, 2016b), we assume that individuals rarely react to climate events as measured objectively, but rather act based on their perceptions of and vulnerability to them (Field et al., 2012; Dessai et al., 2004; Zander \& Garrett, 2020; De Longueville et al., 2020; Koubi et al., 2016a, 2016b, 2016c).

Taken together, this first part of our argument (first column in Fig. 1) assumes that the type of climate event affects the ability of individuals to adapt in situ. Perceived sudden/short-term events should leave little to no room for in situ adaptation (path B in Fig. 1) whereas perceived gradual/long-term events likely leave much more leeway to do so (path A in Fig. 1). Having said that, we expect these patterns to be mediated by individual and household characteristics potentially allowing an identification of involuntary immobility.

\section{Individual and household factors as moderators of climate effects}

Beyond the room for adaptation bestowed by a particular climate event, an individual's capacity to adapt in situ is also important for actual mobility dynamics (Carling, 2002). We argue that personal and household-level characteristics moderate the impact

\footnotetext{
1 Migration "aspiration" is defined as "a conviction that migration is preferable to non-migration" (Carling \& Schewel, 2018: 946). As such, it "can take a variety of forms, from lifestyle-driven preferences to urgencies to escape danger, with innumerable possibilities in between" (Carling \& Schewel, 2018: 959). In the context of climate change, we conceive migration aspirations "as urgencies to escape danger.".

2 At the individual level, (im-)mobility is also influenced by place attachment, comfort of familiarity, fear of the unknown, risk aversion, and family obligations (Adams, 2016; Farbotko et al., 2018; Zickgraf, 2018). Unfortunately, we lack data to comprehensively test for these influences.
} 
climate perceptions have on migration (see also Carling, 2002) and that, by modeling these interactive effects, we can better explain climate-induced migration (Baez et al., 2017; Hunter, 2018; Piguet et al., 2011; Thiede \& Gray, 2017; Zickgraf, 2018). Panels 2 and 3 in Fig. 1 summarize this part of our theory.

The range of adaptive options varies among individuals, depending on attributes such as human and financial capital (Field et al., 2012: 67). Individuals with adequate access to resources (e.g., Black et al., 2011; Piguet et al., 2011) or education (e.g., van der Land \& Hummel, 2013) are less vulnerable to climatic changes and, hence, more likely to adapt. Recent studies indeed find that the impact of climatic changes on migration varies considerably among sub-populations with respect to socio-economic indicators (Afifi et al., 2016; Baez et al., 2017; BohraMishra et al., 2017; Gray \& Mueller, 2012; Gray \& Wise, 2016; Thiede \& Gray, 2017; Thiede et al., 2016). For instance, Bohra-Mishra et al. (2017) and Gray and Mueller (2012) suggest that low levels of education may be an important factor impeding climate-related migration. We submit that different climate events are likely to induce diverse effects on the likelihood of an individual migrating given her human (education) and financial (profession and wealth) capital. By jointly considering the chances for adaptation in situ allowed by a certain climate event and an individual's adaptive capacity - as driven by her financial and human capital-we can improve our theoretical leverage in explaining why people migrate or not ${ }^{3}$ in the presence of climatic changes.

On one hand, we argue that sudden/short-term events inflict significant costs on all affected people, thereby leaving, on average, little room for variation in individual adaptive capacity (Warner, 2010). As a result, we expect individual and household characteristics to play a weak role in mediating the effects of climate events on migration in this context (path B in Fig. 1). It is precisely in the case of these sudden climate events where we would expect to see general mobility (Cattaneo et al., 2019; Goldbach, 2017; Warner, 2010)_irrespective of the type or degree of individual capital. That is, following path B in Fig. 1, we expect that migration is more likely in general, i.e., independent of individual level capacity to adapt in situ, in such a scenario. However, if an individual's human or financial capital is significantly associated with a lower likelihood of mobility in the presence of such sudden/short-term events, we argue that this can be interpreted as involuntary immobility (right-hand side panel in Fig. 1). Consequently, if the ability to move is weakly pronounced, migration becomes less likely regardless of the readiness (i.e., motivation) and willingness to do so in the presence of a sudden climate event (Williams \& Gray, 2020).

Gradual/long-term climate events, on the other hand, are initially likely to have a smaller immediate impact, allowing people to adapt (path A in Fig. 1). Accordingly, these events have a different impact on individuals depending on their adaptive

\footnotetext{
3 Only a few studies focus on such immobility (Zickgraf 2018; Nawrotzki \& DeWaard, 2018; BohraMishra et al., 2017; Longan et al., 2016; Gray \& Wise, 2016; Afifi et al., 2016; Warner \& Afifi, 2014; Gray \& Mueller, 2012), suggesting that there exists some "mobility bias" in the literature (Schewel 2020). Therefore, we strive to improve current explanations by looking in more detail at the conditions under which immobility occurs.
} 
capacity. For example, the influence of gradual/long-term climate events is expected to be greater on people who primarily depend on natural and agricultural resources for their livelihood (Thiede \& Gray, 2017; Field et al., 2012). Moreover, those individuals with high adaptive capacities can make use of these capacities to adapt to gradual/long-term climate events (Black et al., 2011; Piguet et al., 2011). That is, although a specific climate event might bring about a certain need to leave, individual adaptive capacity allows for adaptation in situ. In the framework of Schewel (2020), this is considered as voluntary immobility.

Consequently, if specific types of individuals possess a higher adaptive capacity, we expect these to be more likely to choose in situ adaptation over migration. Those who lack adaptive capacity in the presence of gradual/long-term climate events, however, should be more likely to leave. As a result, migration depends to a great extent on individual factors in the case of gradual/long-term climate events (following path A). This leads to the following theoretical expectations. First, people with low capacity to adapt are more likely to migrate (path A.1 in Fig. 1). Second, those able to adapt due to their higher capacity will stay and not migrate (path A.2 in Fig. 1). And third, if those who possess lower adaptive capacities, i.e., the less educated and poorer individuals, are less likely to migrate in the presence of gradual/ long-term climate events, we view this as involuntary immobility. This mechanism is illustrated in Afifi et al. (2016: 257f) who examine rainfall variability and report that "while the most affluent residents had no need to migrate, trapped populations were forced to cope locally with rainfall variability as they did not have resources to facilitate migration."

More precisely, with respect to human capital, individuals with high levels of education should find it easier to adapt to changing climatic conditions and, thus, gradual/long-term climate events do not significantly influence their decision to leave. Staying, in this scenario, then indicates voluntary immobility. Note that this is independent of the general propensity to migrate. While more educated individuals are generally more likely to migrate, this is independent of the type of climate event (Bohra-Mishra et al., 2017; Gray \& Mueller, 2012). Hence, better educated individuals might be more likely to migrate per se; yet, in the presence of gradual/longterm climate events, we should not observe any difference. In contrast, those with low levels of education are likely to find it harder to adapt to gradual climate events.

With respect to financial capital, it is both the type of profession and wealth that determine whether people stay or migrate. Gradual/long-term climate events are more likely to have a greater impact on people who depend on natural and agricultural resources for their livelihood (Thiede \& Gray, 2017; Field et al., 2012). Consequently, farmers and salesmen of farm/forest products may be the most likely to leave. This implies that the opportunity cost for moving decreases and, eventually, is relatively lower in comparison to other professions. Recent studies provide evidence that climatic changes increase the likelihood of migration via a reduction in agricultural yields in the Philippines (Bohra-Misha et al., 2017), India (Dallmann \& Millock, 2017; Viswanathan \& Kumar, 2015), Pakistan (Mueller et al., 2014), and Tanzania (Kubik \& Maurel, 2016). Finally, while wealthy individuals are able to relocate, wealth can still help them to withstand economic hardship and adapt in the presence of long-term climate events (McLeman \& Smit, 2006). 
To recap, we identify involuntary immobility in the context of sudden/short-term climate events if certain sub-populations with low individual capacities stay, since we generally expect a uniform reaction by all types of individuals to move in the presence of these events (path B in Fig. 1). Similarly, in the case of gradual/longterm events, those who are adversely affected and do possess lower adaptive capacities are less likely to migrate. This also constitutes evidence for involuntary immobility (path A1 in Fig. 5). However, people with stronger adaptive capacities are better able to deal with gradual climatic changes and, hence, we observe voluntarily immobile in this case (path A2 in Fig. 1).

\section{Research design}

\section{Survey overview}

For the empirical analysis, we use cross-sectional survey data with the individual respondent as the unit of analysis. The data include both non-migrants and migrants who originally come from the same area experiencing a particular climate event ( $N=3689$ of which 1835 are non-migrants and 1854 are migrants). The individual-level surveys were conducted in five developing countries, namely Vietnam, Cambodia, Uganda, Nicaragua, and Peru between August 2013 and August 2014. We explicitly chose regions within each country that had experienced at least one particular climate event classified either as sudden/short-term or gradual/longterm event. We used the same survey instruments in each country. Interviews were conducted face-to-face in local languages by native interviewers, lasted for about $30 \mathrm{~min}$, and included both closed and open-ended questions pertaining to respondents' experience with climate events as well as personal and household information. Table 1 gives an overview of survey locations and provides additional information, while Table 2 presents descriptive statistics by country for all variables we introduce in the following.

We selected these five countries as they are vulnerable to climate change and regularly experience weather-related events (Kreft \& Eckstein, 2014). The selected countries comprise regions that have experienced different types of climate events. In addition, these countries are located in different areas of the world (Southeast Asia, Sub-Saharan Africa, and Central and Latin America). The rationale for this last selection criterion is to study countries that widely differ in political and economic systems as well as development, but are rather similar in their vulnerability to climate change. Following these criteria, the five countries we chose provide an ideal testing ground for our theory, while external validity is enhanced as we demonstrate that the same relationship between climate events and migration exists across a wider range of countries.

Based on information obtained from the EM-DAT/OFDA/CRED International Disaster Database and archival research, we first identified relevant regions in each survey country that are mainly characterized by one particular climate event. In turn, we first randomly chose the departments/districts for the location of the survey and then randomly selected communes or villages in these departments/districts 


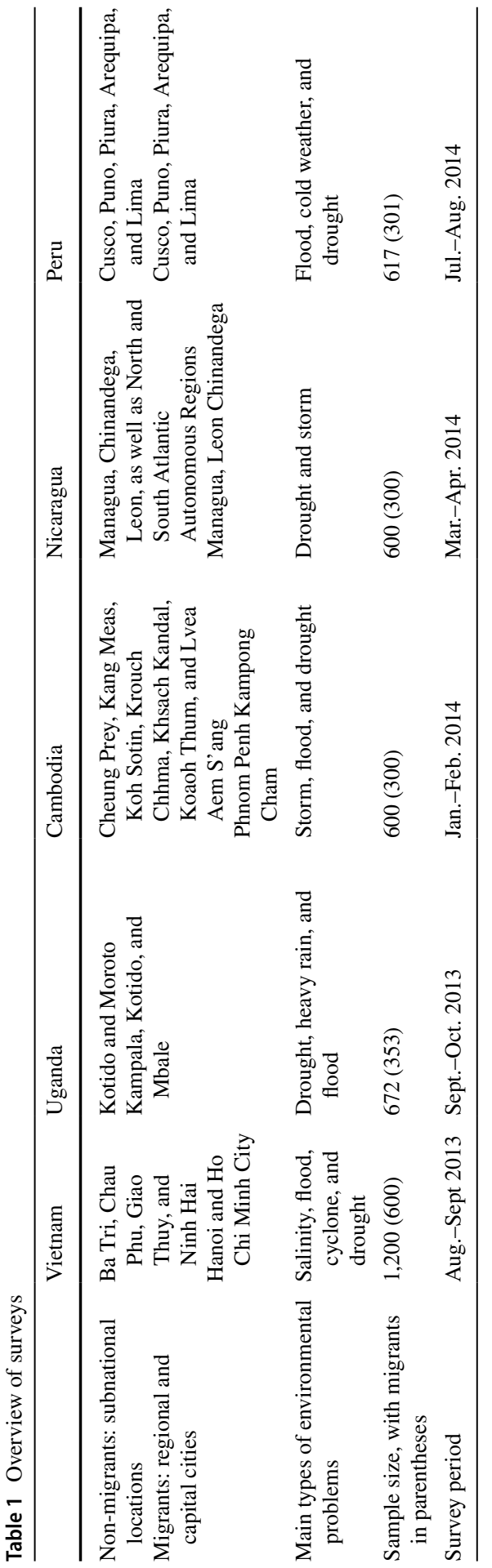


Table 2 Summary statistics for each survey

\begin{tabular}{|c|c|c|c|c|c|}
\hline & Vietnam & Uganda & Cambodia & Nicaragua & Peru \\
\hline Migrants & 0.50 & 0.53 & 0.50 & 0.50 & 0.49 \\
\hline Gradual event & 0.29 & 0.94 & 0.53 & 0.30 & 0.18 \\
\hline Sudden event & 0.82 & 0.29 & 0.95 & 0.59 & 0.81 \\
\hline Female & 0.57 & 0.64 & 0.61 & 0.58 & 0.59 \\
\hline Household member migrated & 0.38 & 0.38 & 0.57 & 0.34 & 0.33 \\
\hline Age & $\begin{array}{l}34.30 \\
(12.04)\end{array}$ & $\begin{array}{l}32.88 \\
(8.32)\end{array}$ & $\begin{array}{l}33.02 \\
(13.75)\end{array}$ & $\begin{array}{l}33.50 \\
(11.86)\end{array}$ & $\begin{array}{l}37.48 \\
(12.48)\end{array}$ \\
\hline Education & $\begin{array}{l}3.17 \\
(0.96)\end{array}$ & $\begin{array}{l}1.30 \\
(0.70)\end{array}$ & $\begin{array}{l}3.28 \\
(1.45)\end{array}$ & $\begin{array}{l}2.85 \\
(1.14)\end{array}$ & $\begin{array}{l}3.01 \\
(1.00)\end{array}$ \\
\hline Household wealth & $\begin{array}{l}1.81 \\
(0.74)\end{array}$ & $\begin{array}{l}1.24 \\
(0.50)\end{array}$ & $\begin{array}{l}1.86 \\
(0.67)\end{array}$ & $\begin{array}{l}1.11 \\
(0.34)\end{array}$ & $\begin{array}{l}1.14 \\
(0.36)\end{array}$ \\
\hline Civil servant & 0.05 & 0.01 & 0.04 & 0.11 & 0.06 \\
\hline Business sales & 0.20 & 0.24 & 0.18 & 0.13 & 0.20 \\
\hline Craft and trade workers & 0.10 & 0.03 & 0.04 & 0.22 & 0.10 \\
\hline Elementary occupations & 0.13 & 0.12 & 0.03 & 0.21 & 0.19 \\
\hline Other sources of income & 0.01 & 0.08 & 0.18 & 0.09 & 0.05 \\
\hline Number of observations & 1,200 & 672 & 600 & 600 & 617 \\
\hline
\end{tabular}

Table entries are mean values; standard deviations for non-binary variables in parentheses

by using a grid system with random starting points in which the interviews of the non-migrants took place. Finally, for the selection of households, from the starting point, interviewers adopted the right-hand rule, skipping every second house. In contrast, a random sampling of migrants is hardly possible, since (by definition) they do not longer live in the same community as non-migrants. Furthermore, in the locations they have migrated to, we do not know ex-ante whether a specific person has migrated from the relevant areas. Hence, we relied on a snowballing or chainreferral process to identify individuals who came from the same locations as nonmigrants, but who left their homes to live elsewhere. This sampling method is frequently used in sociological studies of hidden populations (Laczko \& Aghazarm, 2009). Starting points for the snowballing were obtained by asking non-migrants and identified migrant interviewees whether they knew of any individuals who had left their community after having experienced the same climate event(s) and did not belong to the same household. The migrants found through this process needed to fulfill additional criteria. Specifically, they should have migrated from the affected regions at age 18 or older; they should not be seasonal migrants; they should be residents of this new urban location; and they should earn their livelihood in the new urban location. ${ }^{4}$

\footnotetext{
4 That respondents should earn their livelihood in the new urban location may introduce some bias. First, since the snow-balling procedure started with asking people in the village who chose to stay whether they know people who left, we find migrants with ties to the village more easily than those without such bonds. However, what this implies in terms of the age, education, or wealth structure of migrants is uncertain, since one cannot judge this against any register of migrants (does not exist for any of the countries under investigation). Second, some migrants might have acquired their current level of education or wealth in their new homes. However, if we only include those migrants that had left within the previous
} 


\section{Estimation procedure and variables}

We use multilevel logistic regression models, which are appropriate for the multilevel survey design with a binary dependent variable. All models include countrylevel and regional-level intercepts that account for the hierarchical sampling procedure within countries (Gelman \& Hill, 2007). Recall that while specific regions in each of the surveyed countries were chosen deliberately, random sampling followed below this level. To identify a general pattern, we first pool the country surveys and estimate full models based on all countries' data. However, to account for the fact that individual migration profiles might differ to some extent given the various conditions in the respective countries (Gray \& Wise, 2016; Thiede et al., 2016; Field et al., 2012), we also discuss the results individually for each country. Each model's fit is assessed via the log-likelihood values and Wald $\mathrm{x}^{2}$ statistics.

The dependent variable is binary with a value of 1 if a respondent migrated ( 0 for those respondents who stayed and did not migrate). Our main explanatory variables can be grouped into exposure-related items, adaptive-capacity variables, and interactions of these. First, to operationalize individuals' exposure to climate events, we follow existing scholarship and distinguish between sudden/short-term and gradual/long-term events (Koubi et al., 2016a; Field et al., 2012; Renaud et al., 2011; Warner, 2010). Interviewees were asked about the main weather event(s) they had experienced during the past five years. Respondents could choose between several weather events such as heavy rain, floods, or droughts, but could also list any other event that was not listed in the questionnaire. We use this information to construct the variables Sudden Event and Gradual Event, based on previous suggestions to group climate-related events into such categories (e.g., Koubi et al.,2016a, b, c; 2021; Spilker et al., 2020): the former item is about individuals' perceptions of short-term climate events, with values of 1 ( 0 otherwise) if individuals mentioned that they had experienced heavy rain, storms, floods, hurricanes, cyclones, typhoons, and/or landslide/mudslides in their current (if non-migrant) or previous location (if migrant); the variable Gradual Event is about individuals' perceptions of long-term climate events and is coded as 1 ( 0 otherwise) if individuals mentioned that they had experienced salinity, drought, or desertification in their current (if non-migrant) or previous location (if migrant).

The timing of when an event occurred matters somewhat: we focus on period of up to five years between the experience of climate events and migration decisions. Our corresponding survey questions are indeed formulated along this line. ${ }^{5}$ The five-year period was selected as correctly recalling any event occurred many more years before the surveys were conducted would have been less likely. However, we

\footnotetext{
Footnote 4 (continued)

two years, which means that we focus on migrants who hardly had time to acquire significant new levels of education or wealth at their new location, the results are substantively the same (see appendix).

5 Specifically, the survey questions ask: "[f]rom your perspective, can you describe the main weather event(s) that have happened here during the last 5 years? (Non-migrant) - From your perspective, can you describe the main weather event(s) that occurred during the past five years before you left your previous residence? (Migrant).”.
} 
also control for the duration of the stay of non-migrants and migrants in destination areas in a robustness check in the appendix. That is, the survey includes a question on how long respondents have lived in each place. This variable ranges between 0 and 64 years. When re-estimating our main models with a sample of migrants who moved to their new location no more than two years prior to our survey, the results stay the same (Tables 6 and 7 in the appendix).

We capture respondents' adaptive capacity via proxies for financial and human capital that matter for an individual's adaptive capacity: household wealth, profession, and education. The justification is that we can account for most variation in individual adaptive capacity when choosing these proxies, and they are best comparable between our different country contexts (Massey, 1990; see also Nawrotzki et al., 2015). First, there is the variable Education, which captures the human-capital aspect. The variable is ordinally scaled and ranges between 1 and 5: the lowest value (1) stands for no formal education, a value of 2 is assigned if a respondent received at maximum primary education, the value of 3 pertains to secondary education at best, the value of 4 is given for technical education, and the highest value (5) is assigned if a respondent received post-secondary education. Second, there is an ordinally scaled variable for wealth, which measures individuals' financial capital (Household Wealth). This variable denotes interviewers' classification of a respondent's overall (household) economic conditions: below average income, average income, or above average income. The coding of this variable is based on the interviewers' observation of the respondents' house structure (ranging from a hut to a brick house) as well as ownership of some durable goods, while the scale of the item(s) had been determined before the interviews had commenced. Third, a categorical variable codes individuals' Profession. Originally, the survey asked about the most important source of household income and distinguished between ten different professions. We selected these ten answer categories as they capture virtually all possible income sources in the respective countries. Eventually, we focus on the most dominant categories when distinguishing between civil servants, business sales, craft and trade workers, elementary occupations (e.g., day labor), and individuals working in the agriculture sector. We use the latter as the baseline category and construct a series of dummy variables based on the other categories. The categories are mutually exclusive and exhaustive. While an individual's profession is often seen as part of her human capital, we conceive of it as financial capital as a person's profession greatly determines her financial resources in the countries we study.

To get to the core of our theory, namely the interplay of exposure and adaptive capacity, we constructed multiplicative interaction terms. That is, we multiply all exposure items with the adaptive-capacity variables. Interpreting multiplicative interaction specifications can be challenging as their coefficients hardly allow for a direct reading of signs and significance levels. Hence, following Brambor et al. (2006), we estimated marginal effects for all relevant scenarios and present these in graphical form to facilitate interpretation.

Finally, all interviewers asked a list of personal information that we use as control variables. These items account for known differences in the probability of migration by age, gender, and the previous migration of a family member (see Adger et al., 2015; Hunter et al., 2015; McLeman, 2014). To this end, we include the variables 
Age (ranging from 18 to 85), Female (receiving a value of 1 for female respondents, 0 otherwise), and Household Migrated (1 if a household member had migrated before, 0 otherwise $)^{6}$ in our models.

\section{Empirical results}

Our main models are summarized in Tables 3 and 4. In model 1, we do not include the adaptive-capacity variables or their interactions with the exposure items. Instead, we solely focus on the unconditional effect of climate events on migration. Model 2 shows the interaction between human capital, measured by the item for education, and the variables on sudden/short-term and gradual/long-term climate events. Model 3 presents the results for the financial-capital variable measured by household wealth. And model 4 (Table 4) concentrates on the interaction of the profession-related variables and climate events. We show substantive quantities of interest in the form of average marginal effects according to each moderating factor (Figs. 2-4).

Starting with model 1, the exposure to gradual events decreases the likelihood of migration, while having experienced short-term events raises the chances to relocate. Both variables' coefficient estimates are statistically significant. While these baseline effects are interesting, they ignore the influence of an interaction with the variables that capture individuals' capacity to adapt. We introduce these now, one at a time in models $2-4$.

The education variable, our proxy for human capital, and the corresponding interactions with the exposure variables are the focus of model 2 . We see that the coefficient for education in model 2 is positively signed and statistically significant, suggesting that more educated individuals are more likely to migrate. But how does this interact with the variables for gradual and sudden events? Both interaction terms are positively signed and statistically significant in model 2 , but a direct interpretation is difficult based on coefficients alone (see Brambor et al., 2006). Figure 2 depicts the impact of gradual/long-term (left panel) and sudden/short-term climate events (right panel) given different levels of education in the form of average marginal effects. It is evident that the significant impact of either climate event on migration is dependent on an individual's education. The perception of gradual/long-term climate events decreases the probability of migration only for individuals with low levels of education. In contrast, more educated people are linked to insignificant average marginal effects. Hence, education offsets the negative impact stemming from gradual events. These results provide some evidence that involuntary immobility exists: in line with our Fig. 1, we expect that those with lower capacities to adapt in situ are more likely to migrate (Path A.1). Further note that individuals are only more likely to migrate in the presence of sudden/short-term climate events given at least a "moderate" level of education (where the education variable receives a value of 3 or higher). However, assuming a mostly uniform necessity to migrate in the presence of sudden/ short-term events, one would expect all individuals to have a similarly heightened

\footnotetext{
6 The question in the survey asks: "[u]p until now, have members of your household left temporarily or permanently for other places or even abroad?".
} 
Table 3 Multilevel logistic regression models of migration for residents of climate event-affected regions of Vietnam, Cambodia, Uganda, Nicaragua, and Peru

\begin{tabular}{|c|c|c|c|}
\hline & Model 1 & Model 2 & Model 3 \\
\hline Gradual event & $\begin{array}{l}-0.61 * * \\
(0.10)\end{array}$ & $\begin{array}{l}-1.37 * * \\
(0.29)\end{array}$ & $\begin{array}{l}-0.48 \\
(0.27)\end{array}$ \\
\hline Sudden event & $\begin{array}{l}0.39 * * \\
(0.11)\end{array}$ & $\begin{array}{l}-0.44 \\
(0.26)\end{array}$ & $\begin{array}{l}-1.04 * * \\
(0.28)\end{array}$ \\
\hline Female & $\begin{array}{l}0.09 \\
(0.08)\end{array}$ & $\begin{array}{l}0.22 * \\
(0.09)\end{array}$ & $\begin{array}{l}0.30 * * \\
(0.09)\end{array}$ \\
\hline Household member migrated & $\begin{array}{l}0.41^{* *} \\
(0.08)\end{array}$ & $\begin{array}{l}0.37 * * \\
(0.09)\end{array}$ & $\begin{array}{l}0.37 * * \\
(0.09)\end{array}$ \\
\hline Age & $\begin{array}{l}-0.09 * * \\
(0.00)\end{array}$ & $\begin{array}{l}-0.06^{* * *} \\
(0.00)\end{array}$ & $\begin{array}{l}-0.06^{* *} \\
(0.00)\end{array}$ \\
\hline Education & & $\begin{array}{l}0.32 * * \\
(0.06)\end{array}$ & \\
\hline Gradual event*education & & $\begin{array}{l}0.25 * * \\
(0.09)\end{array}$ & \\
\hline Sudden event*education & & $\begin{array}{l}0.32 * * \\
(0.09)\end{array}$ & \\
\hline Household wealth & & & $\begin{array}{l}0.22 \\
(0.19)\end{array}$ \\
\hline Gradual event* household wealth & & & $\begin{array}{l}0.06 \\
(0.16)\end{array}$ \\
\hline Sudden event* household wealth & & & $\begin{array}{l}0.87 * * \\
(0.19)\end{array}$ \\
\hline Constant & $\begin{array}{l}2.84 * * \\
(0.48)\end{array}$ & $\begin{array}{l}1.18 \\
(0.73)\end{array}$ & $\begin{array}{l}1.43 \\
(0.65)\end{array}$ \\
\hline Observations & 3625 & 3614 & 3125 \\
\hline Number of groups (variance) - country & $5(0.19)$ & $5(1.44)$ & $5(0.84)$ \\
\hline Number of groups (variance) - district & $27(4.33)$ & $27(3.97)$ & $27(4.01)$ \\
\hline Log likelihood & -1917.37 & -1797.52 & -1535.54 \\
\hline Wald $x^{2}$ & $533.43 * *$ & $637.21 * *$ & $381.95^{* *}$ \\
\hline
\end{tabular}

Table entries are coefficients from multilevel logistic regression models with country level and district level random effects; standard errors in parentheses; * $p<0.05 ; * * p<0.01$

likelihood to move (path B in Fig. 1). As this is not the case for those with the lowest level of education, this finding is again indicative of involuntary immobility.

We continue with a respondent's financial capital endowment, i.e., model 3. Only the interaction coefficient with the sudden-event variable is significant (positively signed). Again, though, as an interpretation based on coefficients is challenging, we shift our focus to Fig. 3. With regard to sudden events, individuals coming from poor households are estimated to have a significantly lower likelihood to migrate in the presence of sudden/short-term climate events (right panel). Having expected a higher likelihood of migration irrespective of individual and household characteristics in the aftermath of a sudden-onset climate event, our empirical result again supports an interpretation in line with involuntary immobility. This finding is in line with path B in Fig. 1. Interestingly, in the presence of gradual/long-term 
Table 4 Multilevel logistic regression models of migration for residents of climate eventsaffected regions of Vietnam, Cambodia, Uganda, Nicaragua, and Peru: profession-related variables

\begin{tabular}{|c|c|}
\hline & Model 4 \\
\hline Gradual event & $\begin{array}{l}-0.68^{* *} \\
(0.14)\end{array}$ \\
\hline Sudden event & $\begin{array}{l}0.54^{*} \\
(0.16)\end{array}$ \\
\hline Female & $\begin{array}{l}0.12 \\
(0.09)\end{array}$ \\
\hline Household member migrated & $\begin{array}{l}0.41 * * * \\
(0.09)\end{array}$ \\
\hline Age & $\begin{array}{l}-0.08^{* *} \\
(0.00)\end{array}$ \\
\hline Civil servant & $\begin{array}{l}-1.32 \\
(0.43)\end{array}$ \\
\hline Civil servant*sudden event & $\begin{array}{l}0.59 \\
(0.45)\end{array}$ \\
\hline Civil servant*gradual event & $\begin{array}{l}1.18^{*} \\
(0.44)\end{array}$ \\
\hline Business sales & $\begin{array}{l}-0.61 \\
(0.27)\end{array}$ \\
\hline Business sales*sudden event & $\begin{array}{l}0.18 \\
(0.27)\end{array}$ \\
\hline Business sales*gradual event & $\begin{array}{l}-0.14 \\
(0.25)\end{array}$ \\
\hline Craft and trade workers & $\begin{array}{l}-1.05^{* *} \\
(0.32)\end{array}$ \\
\hline Craft and trade*sudden event & $\begin{array}{l}-0.53 \\
(0.34)\end{array}$ \\
\hline Craft and trade* ${ }^{*}$ gradual event & $\begin{array}{l}0.38 \\
(0.34)\end{array}$ \\
\hline Elementary occupation & $\begin{array}{l}-0.19 \\
(0.29)\end{array}$ \\
\hline Elementary*sudden event & $\begin{array}{l}-0.72 * \\
(0.30)\end{array}$ \\
\hline Elementary*gradual event & $\begin{array}{l}-0.27 \\
(0.28)\end{array}$ \\
\hline Other sources of income & $\begin{array}{l}0.39 \\
(0.47)\end{array}$ \\
\hline Other sources*sudden event & $\begin{array}{l}-0.70 \\
(0.53)\end{array}$ \\
\hline Other sources* gradual event & $\begin{array}{l}-1.39 * \\
(0.55)\end{array}$ \\
\hline Constant & $\begin{array}{l}3.14 \\
(0.46)\end{array}$ \\
\hline Observations & 3,477 \\
\hline Log likelihood & $-1,791.06$ \\
\hline Wald $x^{2}$ & $571.93^{* *}$ \\
\hline
\end{tabular}


Table 4 (continued)

Table entries are coefficients from multilevel logistic regression models with country level and district level random effects; standard errors in parentheses; number of groups at state level: 5 (variance estimate of 0.00); number of groups at district level: 27 (variance estimate of 4.29); * $p<0.05 ; * * p<0.01$

climate events, there is hardly any evidence for a substantive interaction (left panel in Fig. 3). Ultimately, a genuine conditional effect only materializes in the presence of sudden/short-term climate events.

We also analyze the various occupations and how the corresponding individuals react in the presence of gradual/long-term vs. sudden/short-term climate events. We summarize the results in model 4 (Table 4) and provide the various marginal effect plots in Fig. 4. Generally, the results provide a somewhat mixed picture. For example, individuals in elementary occupations are less likely to migrate in the presence of sudden/short-term climate events. However, this must not necessarily mean that these individuals are immobile, since people employed in the industry or the construction sector might simply not want to lose their job. In addition, it could also be that these individuals are the most likely to find jobs when reconstruction/rebuilding starts after a climate event (Halliday, 2006; Mueller \& Quisumbing, 2012). Similarly, the insignificant findings for those owning their own business or living from sales might stem from the fact that they own property and, thus, do not have a real opportunity to move while the latter are more mobile to start with.

Regarding the control variables, our regression results show that females, younger individuals, and people with a household member who had migrated before are more likely to relocate. This is demonstrated by the significant effects of the coefficients for the female variable (positive coefficient, although not significant in model 1), the item for the previous migration of a family member (positive and significant coefficient), and the age item (negative and significant coefficient).

We also consider the effect human and financial capital on migration individually for each country. Table 5 provides an overview of the results, showing that migration patterns in the five countries differ to some extent. For example, in both Peru and Uganda, individuals from poor households are less likely to migrate in the presence
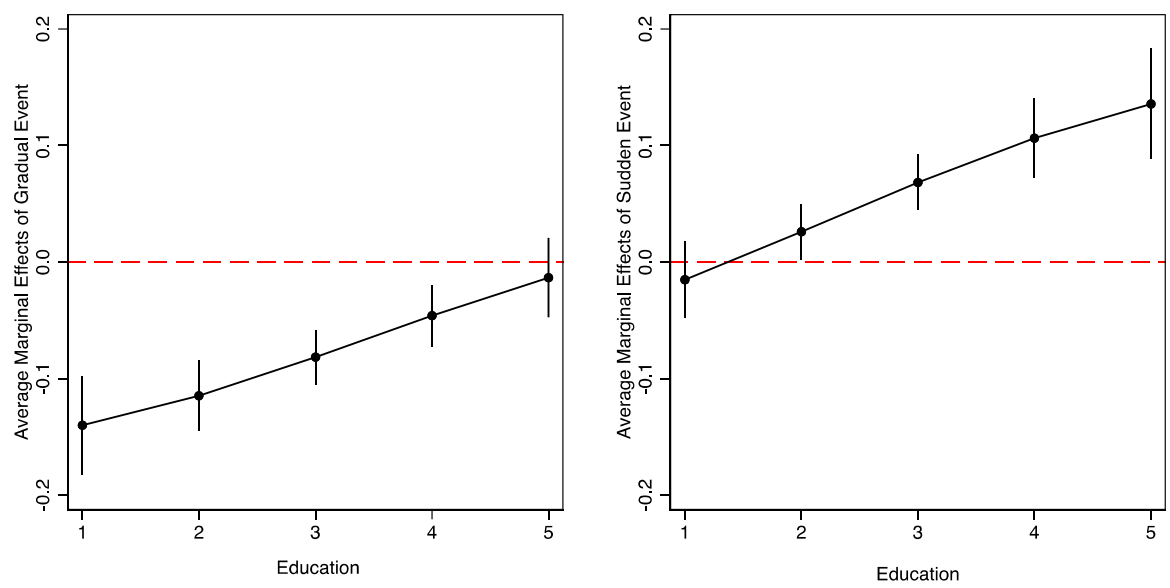

Fig. 2 The impact of climate events conditional on education 

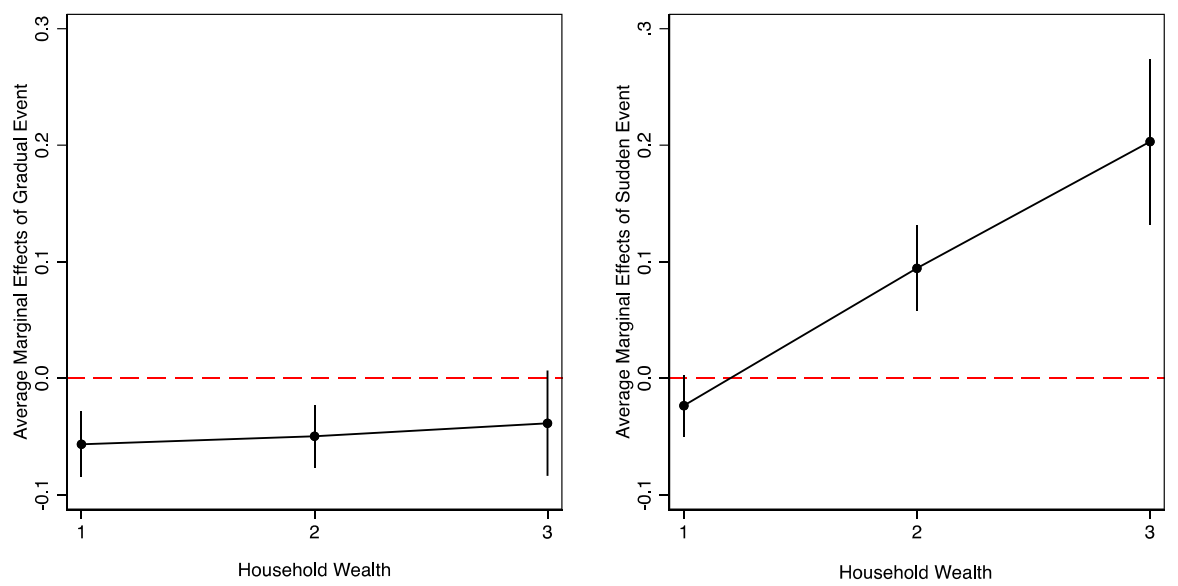

Fig. 3 The impact of climate events conditional on household wealth

of either climate event, which is consistent with the expectations expressed in paths A and B in Fig. 1 as well as the notion of involuntary immobility beyond individuals' adaptive capacity. In Nicaragua, conversely, individuals from poor households are more likely to migrate in the presence of climate events. The same applies to respondents in Cambodia in the presence of gradual events. These patterns go against the moderating influence we would expect according to path A in Fig. 1. In terms of the education item and its interaction with the climate events variables, the positive effect
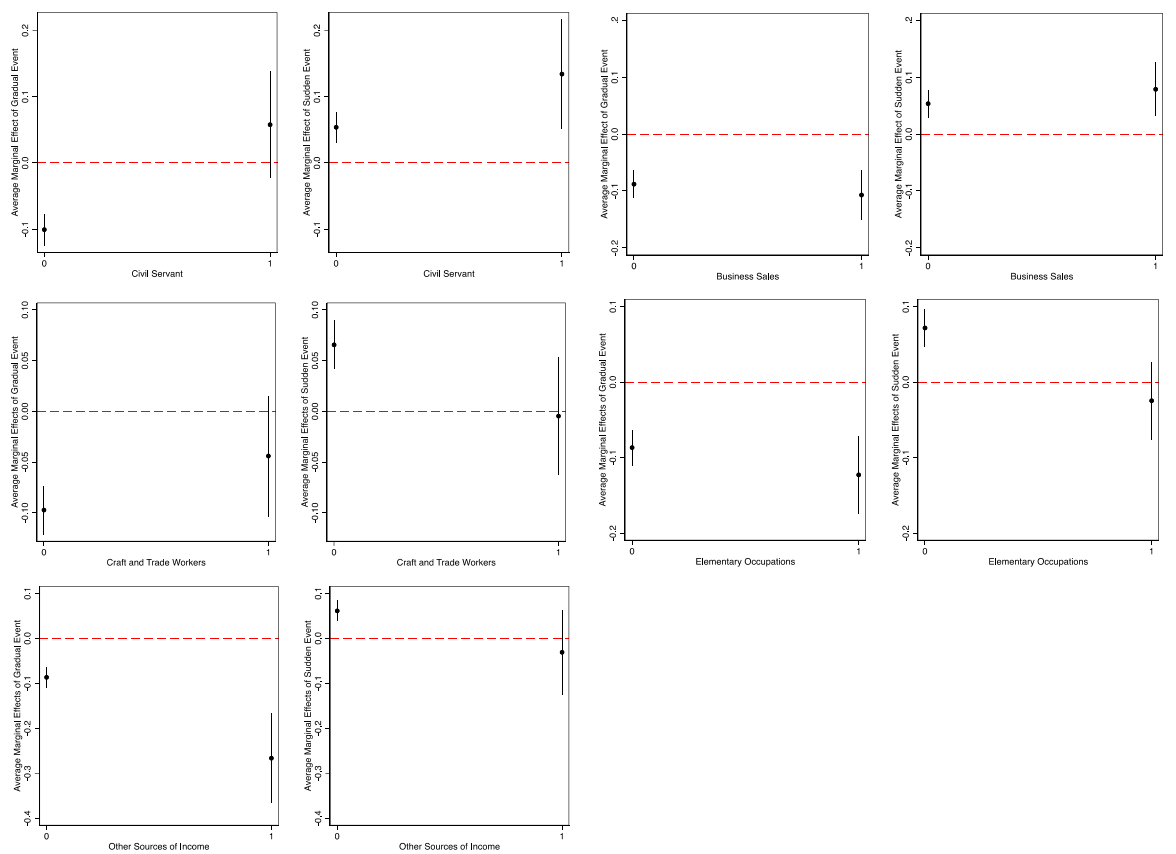

Fig. 4 Conditional effect plots by occupation categories 


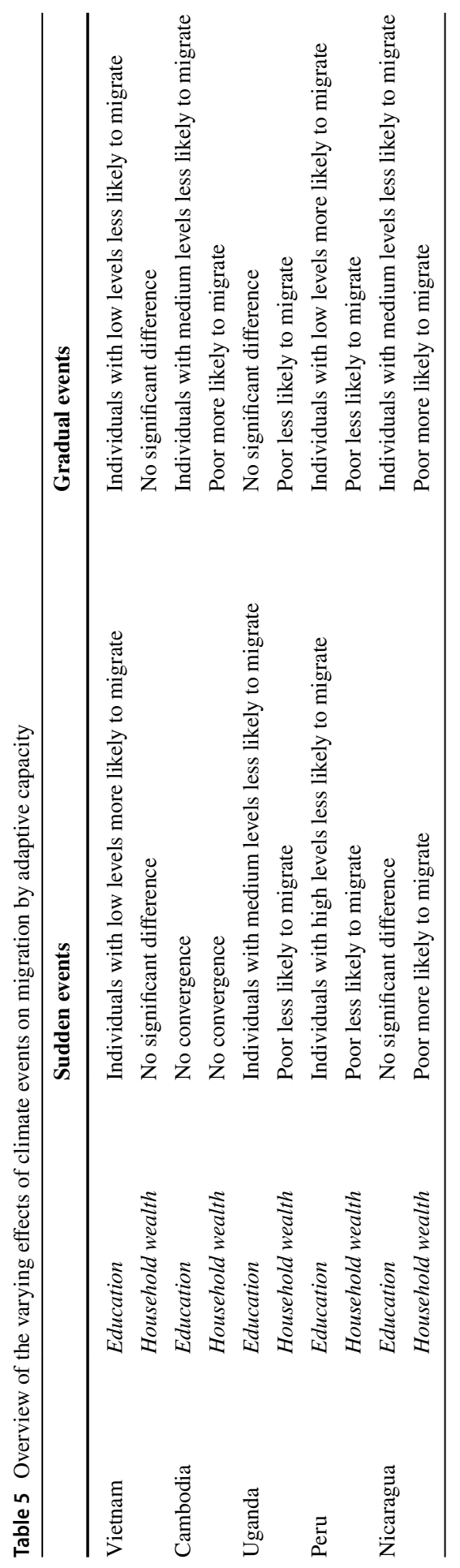


on migration we identified generally across all countries (model 2 in Table 3 and Fig. 2) materializes in Vietnam (gradual events), Nicaragua, and Cambodia (medium levels of education and gradual events only), as well as Uganda (medium levels of education and sudden events only). In Peru (gradual events, path A in Fig. 1) and Vietnam (sudden events, path B in Fig. 1), we actually obtain evidence for patterns going against the general effect, namely that less educated individuals are more likely to relocate. Ultimately, this disaggregation exercise suggests that general patterns may vary across country contexts, highlighting that our general model may have to be somewhat refined if we focus on a single country one at a time.

\section{Conclusion}

Our study is novel in providing a theoretical framework and empirical analysis linking individuals' adaptive capacity and the context of different climate events to their propensity to migrate within different country contexts. Generally, our findings provide evidence that less educated and lower-income people are less likely to migrate after exposure to sudden-onset climate events compared to their counterparts with higher levels of education and economic resources. This mechanism, as outlined in path B of Fig. 1, underlines the need to be cautious of sweeping predictions as expressed in the recent "Groundswell" report that millions of people will move within their countries due to climatic changes, in particular droughts (Rigaud et al., 2018). Although exposure to climate-related events can trigger migration, mobility depends on both the type of the climate event individuals experience and their adaptive capacity.

This research highlights that the differentiated constraints on migration ability are important for actual migration behavior, since lacking human and financial capital seems to be a prime reason for immobility in the presence of climatic changes (see also Carling \& Schewel, 2018; Fussell, 2018; Bohra-Mishra et al., 2017; Thiede et al., 2016; Gray \& Mueller, 2012). For example, individuals with a low level of education are less likely to migrate when facing any type of climate event. Similarly, low-income individuals are much more likely to stay in the presence of both types of climate events. This is mainly worrisome in the case of sudden/shortterm climate events (path B in Fig. 1), where we expect to see a "uniformly" high rate to migrate. Finally, we find that agricultural workers are more likely to relocate, but those with elementary, i.e., mainly day-to-day jobs, tend to stay.

According to our work, while future climatic changes might force people to move from vulnerable places, affected individuals possessing the least capacity to adapt to/ cope with climate change might be immobile. Subsequently, national and international efforts must improve the supply of humanitarian aid to areas affected by short-term climate events and, at the same time, increase the financial and technical support for effective adaptation to long-term climate events, minimizing thus the necessity to move.

Given that climate change is expected to act as a poverty multiplier (Hallegatte \& Rozenberg, 2017; Rigaud et al., 2018; Schwerdtle et al., 2018), future research should further examine the conditions that lead to the (im-)mobility of vulnerable populations, arguably along the conceptual framework suggested by Schewel 
(2020) and Carling and Schewel (2018). In addition, we could study how political marginalization as well as cultural beliefs and barriers influence the inability to move in the face of climatic changes (e.g., Zickgraf, 2019). Third, our sampling strategy to rely on snowballing for the identification of migrants might have introduced some biases that are hard to control post hoc. Future research may strive to improve on our efforts to interview both migrants and non-migrants if this research was conducted in places with official registry of internal migrants. Finally, we did not directly ask our respondents to state whether they would desire to migrate. In reference to the conceptual account by Black et al. (2011), it is, however, pivotal to identify this sub-group in order to assess comprehensively "trapped" populations.

\section{Appendix}

Table 6 Multi-Level Regression Models - Subsample of Respondents Living in Place up to Two Years

\begin{tabular}{|c|c|c|}
\hline & Model 1 & Model 2 \\
\hline \multirow[t]{2}{*}{ Gradual Event } & $-2.53 * *$ & -0.40 \\
\hline & $(0.51)$ & $(0.43)$ \\
\hline \multirow[t]{2}{*}{ Sudden Event } & 0.39 & -0.36 \\
\hline & $(0.58)$ & $(0.48)$ \\
\hline \multirow[t]{2}{*}{ Female } & $0.32 *$ & $0.35 *$ \\
\hline & $(0.14)$ & $(0.15)$ \\
\hline \multirow[t]{2}{*}{ Household Member Migrated } & $0.34 *$ & 0.23 \\
\hline & $(0.14)$ & $(0.16)$ \\
\hline \multirow[t]{2}{*}{ Age } & $-0.10 * *$ & $-0.10 * *$ \\
\hline & $(0.01)$ & $(0.01)$ \\
\hline \multirow[t]{2}{*}{ Education } & $0.42 * *$ & \\
\hline & $(0.16)$ & \\
\hline \multirow[t]{2}{*}{ Gradual Event*Education } & $0.65^{* *}$ & \\
\hline & $(0.15)$ & \\
\hline \multirow[t]{2}{*}{ Sudden Event*Education } & 0.09 & \\
\hline & $(0.17)$ & \\
\hline \multirow[t]{2}{*}{ Household Wealth } & & $1.15^{* *}$ \\
\hline & & $(0.34)$ \\
\hline \multirow[t]{2}{*}{ Gradual Event* Household Wealth } & & 0.11 \\
\hline & & $(0.24)$ \\
\hline \multirow[t]{2}{*}{ Sudden Event* Household Wealth } & & 0.51 \\
\hline & & $(0.32)$ \\
\hline \multirow[t]{2}{*}{ Constant } & 1.23 & -1.63 \\
\hline & $(0.73)$ & $(1.21)$ \\
\hline Observations & 2,329 & 2,193 \\
\hline Log Likelihood & -743.89 & -634.23 \\
\hline Wald $x^{2}$ & $399.77 * *$ & $252.41 * *$ \\
\hline
\end{tabular}

Table entries are coefficients from multilevel logistic regression models with country level and district level random effects; standard errors in parentheses.

$* \mathrm{p}<0.05 ; * * \mathrm{p}<0.01$. 
Table 7 Multi-Level Regression Models - Binary Indicators for Wealth and Education

\begin{tabular}{|c|c|c|}
\hline & Model 3 & Model 4 \\
\hline Gradual Event & $\begin{array}{l}-0.82 * * \\
(0.12)\end{array}$ & $\begin{array}{l}-0.28 \\
(0.15)\end{array}$ \\
\hline Sudden Event & $\begin{array}{l}0.36^{* *} \\
(0.12)\end{array}$ & $\begin{array}{l}-0.16 \\
(0.14)\end{array}$ \\
\hline Female & $\begin{array}{l}0.19^{*} \\
(0.09)\end{array}$ & $\begin{array}{l}0.30 * * \\
(0.09)\end{array}$ \\
\hline Household Member Migrated & $\begin{array}{l}0.37 * * \\
(0.09)\end{array}$ & $\begin{array}{l}0.36^{* *} \\
(0.10)\end{array}$ \\
\hline Age & $\begin{array}{l}-0.07 * * \\
(0.00)\end{array}$ & $\begin{array}{l}-0.07 * * \\
(0.00)\end{array}$ \\
\hline Education Binary & $\begin{array}{l}1.244 * * \\
(0.28)\end{array}$ & \\
\hline Gradual Event*Education & $\begin{array}{l}1.19 * * \\
(0.27)\end{array}$ & \\
\hline Sudden Event*Education & $\begin{array}{l}0.14 \\
(0.29)\end{array}$ & \\
\hline Household Wealth Binary & & $\begin{array}{l}0.46 \\
(0.25)\end{array}$ \\
\hline Gradual Event* Household Wealth & & $\begin{array}{l}0.23 \\
(0.21)\end{array}$ \\
\hline Sudden Event* Household Wealth & & $\begin{array}{l}1.07 * * \\
(0.25)\end{array}$ \\
\hline Constant & $\begin{array}{l}2.01 * * \\
(0.56)\end{array}$ & $\begin{array}{l}1.63 * * \\
(0.60)\end{array}$ \\
\hline Observations & 3,614 & 3,125 \\
\hline Log Likelihood & $-1,783.25$ & $-1,542.60$ \\
\hline Wald $x^{2}$ & $656.61 * *$ & $372.12 * *$ \\
\hline
\end{tabular}

Table entries are coefficients from multilevel logistic regression models with country level and district level random effects; standard errors in parentheses.

$* \mathrm{p}<0.05 ; * * \mathrm{p}<0.01$. 

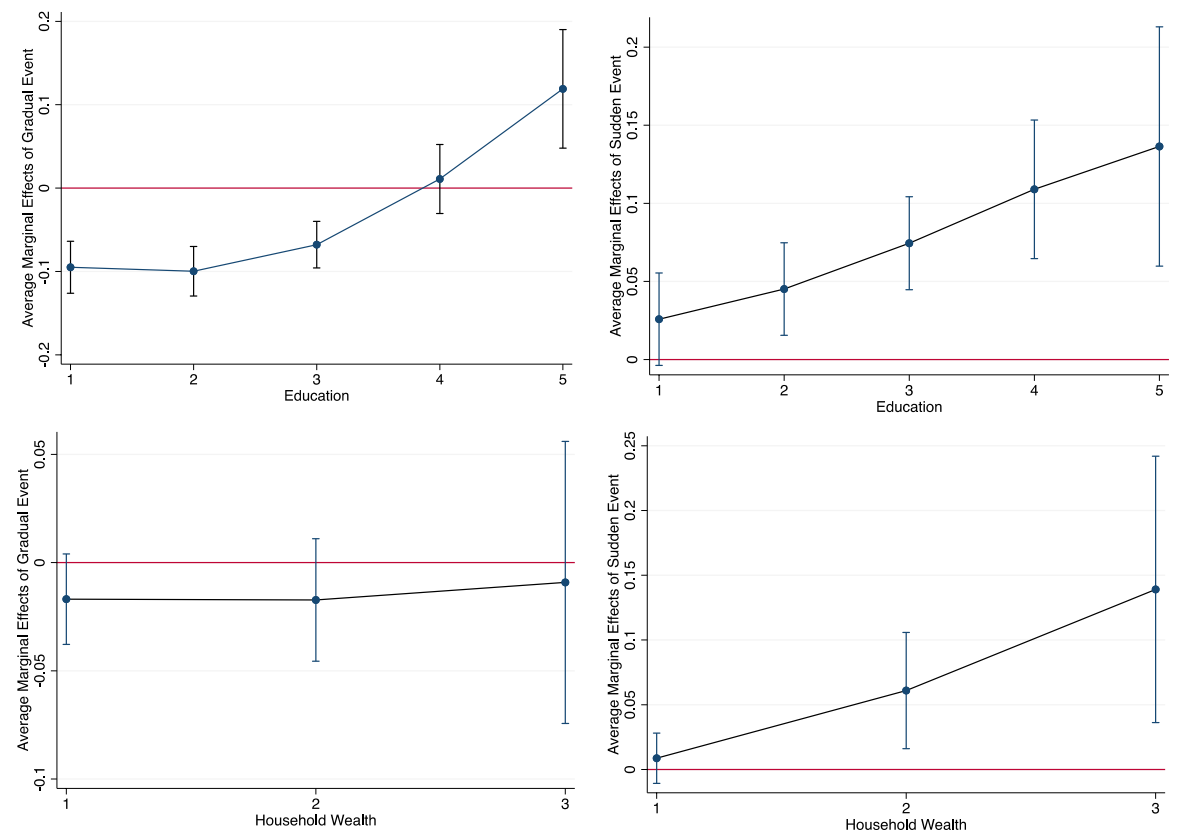

Fig. 5. The Impact of Climate Events Conditional on Education or Household Panels show average marginal effects (solid line) based on the same specification as in Model 1 in Table A.1 (top row) or Model 2 in Table A.1 (bottom row), but with only those migrants who came to their new location within the previous two years. The graphs are based on a multiplicative specification, while all other variables are held at their mean values. Vertical bars pertain to 95 percent confidence intervals using the method in Schenker and Gentleman (2001). Horizontal red line marks average marginal effect of 0 . Numerical values of Education stand for: (1) no formal education, (2) primary school, (3) secondary school, (4) technical school, (5) post-secondary school. Numerical values of Household Wealth stand for: (1) below average, (2) at average, (3) above average.

Acknowledgements The authors are grateful to three anonymous referees and in particular to the editor of P\&E for excellent comments that helped to improve the article.

Funding This research is part of the project "Environmental Change and Migration" funded by the Swiss Network for International Studies (SNIS).

\section{Declarations}

Conflict of interest The authors declare no competing interests.

Open Access This article is licensed under a Creative Commons Attribution 4.0 International License, which permits use, sharing, adaptation, distribution and reproduction in any medium or format, as long as you give appropriate credit to the original author(s) and the source, provide a link to the Creative Commons licence, and indicate if changes were made. The images or other third party material in this article are included in the article's Creative Commons licence, unless indicated otherwise in a credit line to the material. If material is not included in the article's Creative Commons licence and your intended use is not permitted by statutory regulation or exceeds the permitted use, you will need to obtain permission 
directly from the copyright holder. To view a copy of this licence, visit http://creativecommons.org/ licenses/by/4.0/.

\section{References}

Adams, H. (2016). Why populations persist: Mobility, place attachment and climate change. Population \& Environment, 37, 429-448.

Adger, W. N., Safra de Campos, R., \& Mortreux, C. (2018). Mobility, displacement and migration, and their interactions with vulnerability and adaptation to environmental risks. In R. McLeman \& F. Gemenne (Eds.), Routledge Handbook of Environmental Displacement and Migration (pp. 29-41). Routledge.

Adger NW, Arnell NW, Black R, Dercon S, Geddes A, Thomas D. S. G. (2015). Focus on environmental risks and migration: Causes and consequences. Environmental Research Letters 10: 060201.

Afifi, T., Milan, A., Etzold, B., Schraven, B., Rademacher-Schulz, C., Sakdapolrak, P., Reif, A., van der Geest, A., \& Warner, K. (2016). Human mobility in response to rainfall variability: Opportunities for migration as a successful adaptation strategy in eight case studies. Migration and Development, 5, 254-274.

Al-Amin, A. K. M. A., Akhter, T., Islam, A. H. M. S., Jahan, H., Hossain, M. J., Prodhan, M. M. H., Mainuddin, M., \& Kirby, M. (2019). An intra-household analysis of farmers' perceptions of and adaptation to climate change impacts: Empirical evidence from drought prone zones of Bangladesh. Climatic Change, 156(4), 545-565.

Ayeb-Karlsson, S., Smith, S. D., \& Kniveton, D. (2018). A discursive review of the textual use of 'trapped' in environmental migration studies: The conceptual birth and troubled teenage years of trapped populations. Ambio, 47, 557-573.

Baez, J., Caruso, G., Mueller, V., \& Niu, C. (2017). Droughts augment youth migration in Northern Latin America and the Caribbean. Climatic Change, 140, 423-435.

Black, R., Adger, W. N., Arnell, N. W., Dercon, S., Geddes, A., \& Thomas, D. S. G. (2011). The effect of environmental change on human migration. Global Environmental Change, 21, 3-11.

Black, R., Arnell, N. W., Adger, W. N., Thomas, D., \& Geddes, A. (2013). Migration, immobility, and displacement outcomes of extreme events in nature and society. Environmental Science \& Policy, 27, S32-S43.

Black, R., \& Collyer, M. (2014). Populations 'trapped' at times of crisis. Forced Migration Review, 45, 52-56.

Bohra-Mishra, P., Oppenheimer, M., Cai, R., Feng, S., \& Licker, R. (2017). Climate variability and migration in the Philippines. Population \& Environment, 38, 286-308.

Bohra-Mishra, P., Oppenheimer, M., \& Hsiang, S. M. (2014). Nonlinear permanent migration response to climatic variations but minimal response to disasters. Proceeding of National Academy of Science, 111, 9780-9785.

Brambor, T., Clark, W., \& Golder, M. (2006). Understanding interaction models: Improving empirical analyses. Political Analysis, 14, 63-82.

Carling, J. (2002). Migration in the age of involuntary immobility: Theoretical reflections and Cape Verdean experiences. Journal of Ethnic and Migration Studies, 28(1), 5-42.

Carling, J., \& Schewel, K. (2018). Revisiting aspiration and ability in international migration. Journal of Ethnic and Migration Studies, 44(6), 945-963.

Cattaneo, C., Beine, M., Fröhlich, C., Kniveton, D., Martinez-Zarzoso, I., Mastrorillo, M., Millock, K., Piguet, E., \& Schraven, B. (2019). Human migration in the era of climate change. Review of Environmental Economics and Policy, 13, 189-206.

Dallmann, I., \& Millock, K. (2017). Climate variability and inter-state migration in India. Cesifo Economic Studies, 63, 560-594.

De Longueville, F., Ozer, P., Gemenne, F., Henry, S., Mertz, O., \& Nielsen, J. Ø. (2020). Comparing climate change perceptions and meteorological data in rural West Africa to improve the understanding of household decisions to migrate. Climatic Change, 160, 123-141.

Dessai, S., Adger, W. N., Hulme, M., Turnpenny, J., Köhler, J., \& Warren, R. (2004). Defining and experiencing dangerous climate change: An editorial essay. Climatic Change, 64, 11-25. 
EM-DAT: The OFDA/CRED International Disaster Database. Université Catholique de Louvain, Brussels (Belgium), www.emdat.be

Farbotko, C., McMichael, C., Dun, O., Ransan-Cooper, H., McNamara, K. E., \& Thornton, F. (2018). Transformative mobilities in the Pacific: Promoting adaptation and development in a changing climate. Asia and the Pacific Policy Studies, 5(3), 393-407.

Field CB, Barros V, Stocker TF, Qin D, Dokken DJ, Ebi KL, Mastrandrea MD, Mach KJ, Plattner GK, Allen SK, Tignor M, Midgley PM (eds.) (2012). IPCC. 2012. Managing the risks of extreme events and disasters to advance climate change adaptation. A special report of working groups I and II of the Intergovernmental Panel on Climate Change. Cambridge University Press, Cambridge, UK, and New York, NY, USA.

Foresight: Migration and Global Environmental Change. (2011). Final Project Report. London: The Government Office for Science. Available at: http://www.bis.gov.uk/foresight/\%20migration

Fussell, E. (2018). Population displacements and migration patterns in response to Hurricane Katrina. In R. McLeman \& F. Gemenne (Eds.), Routledge Handbook of Environmental Displacement and Migration (pp. 277-288). Routledge.

Gelman, A., \& Hill, J. (2007). Data analysis using regression and multilevel/hierarchical models. Cambridge University Press.

Gemenne, F., \& Blocher, J. (2017). How can migration serve adaptation to climate change? Challenges to fleshing out a policy ideal. The Geographical Journal, 183(4), 336-347.

Goldbach, C. (2017). Out-migration from coastal areas in Ghana and Indonesia-The role of Environmental factors. Cesifo Economic Studies, 63, 529-559.

Gray, C., \& Mueller, V. (2012). Droughts and population mobility in rural Ethiopia. World Development, $40,134-145$.

Gray, C., \& Wise, E. (2016). Country-specific effects of climate variability on human migration. Climatic Change, 135, 555-568.

Hallegatte, S., \& Rozenberg, J. (2017). Climate change through a poverty lens. Nature Climate Change, 7(4), 250-256.

Halliday, T. (2006). Migration, risk, and liquidity constraints in El Salvador. Economic Development and Cultural Change, 54, 893-925.

Hoffmann, R., Dimitrova, A., Muttarak, R., Cuaresma, J. C., \& Peisker, J. (2020). A meta-analysis of country-level studies on environmental change and migration. Nature Climate Change, 10(10), 1-9.

Hunter, L. (2018). Where do we go from here? Reflections on the future of environmental migration and displacement research. In R. McLeman \& F. Gemenne (Eds.), Routledge Handbook of Environmental Displacement and Migration (pp. 430-435). Routledge.

Hunter, L. M., Luna, J. K., \& Norton, R. M. (2015). Environmental dimensions of migration. Annual Review of Sociology, 41, 1-21.

IPCC-Global Warming of $1.5^{\circ} \mathrm{C}$. (2018). Available at: https://www.ipcc.ch/report/sr15/

Jamero, M. L., Onuki, M., Esteban, M., Billones-Sensano, X. K., Tan, N., Nellas, A., Takagi, H., Thao, N., \& Valenzuela, V. O. (2017). Small-island communities in the Philippines prefer local measures to relocation in response to sea-level rise. Nature Climate Change, 7, 581-588.

Koubi, V., Nguyen, Q., Spilker, G., \& Böhmelt, T. (2021). Environmental migrants and social-movement participation. Journal of Peace Research, 58(1), 18-32.

Koubi, V., Spilker, G., Schaffer, L., \& Böhmelt, T. (2016a). The role of environmental perceptions in migration decision-making: Evidence from both migrants and nonmigrants in five developing countries. Population \& Environment, 38, 134-163.

Koubi, V., Spilker, G., Schaffer, L., \& Bernauer, T. (2016b). Environmental stressors and migration: Evidence from Vietnam. World Development, 79, 197-210.

Koubi, V., Stoll, S., \& Spilker, G. (2016c). Perceptions of environmental change and migration decisions. Climatic Change, 138, 439-451.

Kreft, S., \& Eckstein, D. (2014). Global climate risk index 2014. Who suffers most from extreme weather events? Weather-related loss events in 2012 and 1993 to 2012. Briefing Paper, Germanwatch, Bonn.

Kubik, Z., \& Maurel, M. (2016). Weather shocks, agricultural production and migration: Evidence from Tanzania. Journal of Development Studies, 52, 1-16.

Laczko, F., \& Aghazarm, C. (Eds.). (2009). Migration, environment, and climate change: Assessing the evidence. International Organization for Migration.

Logan, J. R., Issar, S., \& Xu, Z. (2016). Trapped in place? Segmented resilience to hurricanes in the Gulf Coast, 1970-2005. Demography, 53, 1511-1534. 
Massey, D. S. (1990). Social structure, household strategies, and the cumulative causation of migration. Population Index, 56, 3-26.

McLeman, R. (2014). Climate and human migration: Past, experiences, future challenges. Cambridge University Press.

McLeman, R., \& Smit, B. (2006). Migration as an adaptation to climate change. Climatic Change, 76, 31-53.

Missirian, A., \& Schlenker, W. (2017). Asylum applications respond to temperature fluctuations. Science, $358,1610-1614$.

Mueller, V., Gray, C., \& Kosec, K. (2014). Heat stress increases long-term human migration in rural Pakistan. Nature Climate Change, 4, 182-185.

Mueller, V., \& Quisumbing, A. (2012). How resilient are labor markets to natural disasters? The Case of the 1998 Bangladesh flood. Journal of Development Studies, 47, 1954-1971.

Nawrotzki, R. J., \& DeWaard, J. (2018). Putting trapped populations into place: Climate change and interdistrict migration flows in Zambia. Regional Environmental Change, 18, 533-546.

Nawrotzki, R. J., Riosmena, F., Hunter, L. M., \& Runfola, D. M. (2015). Amplification or suppression: Social networks and the climate change-migration association in rural Mexico. Global Environmental Change, 35, 463-474.

Piguet, E., Pécoud, A., \& de Guchteneire, P. (2011). Migration and climate change. Cambridge University Press.

Renaud, F. G., Dun, O., Warner, C., \& Bogardi, J. (2011). A decision framework for environmentally induced migration. International Migration, 49(1), e3-e29.

Rigaud, K. K., de Sherbinin, A., Jones, B., Bergmann, J., Clement, V., Ober, K., Schewe, J., Adamo, S., McCusker, B., Heuser, S., \& Midgley, A. (2018). Groundswell: Preparing for internal climate migration. The World Bank.

Schenker, N., \& Gentleman, J. (2001). On judging the significance of differences by examining the overlap between confidence intervals. The American Statistician, 55, 182-186.

Schewel, K. (2020). Understanding immobility: Moving beyond the mobility bias in migration studies. International Migration Review, 54(2), 328-355.

Schwerdtle, P., Bowen, K., \& McMichael, C. (2018). The health impacts of climate-related migration. BMC Medicine, 16(1), 1.

Soglo, Y. Y., \& Nonvide, G. M. A. (2019). Climate change perceptions and responsive strategies in Benin: The case of maize farmers. Climatic Change, 55(2), 245-256.

Spilker, G., Nguyen, Q., Koubi, V., \& Böhmelt, T. (2020). Attitudes of urban residents towards environmental migration in Kenya and Vietnam. Nature Climate Change, 10(7), 622-627.

Thiede, B., \& Gray, C. (2017). Heterogeneous climate effects on human migration in Indonesia. Population \& Environment, 39, 147-172.

Thiede B, Gray C, Mueller V. (2016). Climate variability and inter-provincial migration in South America, 1970-2011.Global Environmental Change 41: 228-240.

Van der Land V, Hummel D. (2013). Vulnerability and the role of education in environmentally induced migration in Mali and Senegal. Ecology and Society 18: Art. 14.

Viswanathan, B., \& Kumar, K. S. K. (2015). Weather, agriculture and rural migration: Evidence from state and district level migration in India. Environment and Development Economics, 20, 469-492.

Wallemacq P, Below R, McLean D. (2018). Economic losses, poverty \& disasters (1998-2017). Available at: https://www.cred.be/unisdr-and-cred-report-economic-losses-poverty-disasters-1998-2017

Warner, K., \& Afifi, T. (2014). Where the rain falls: Evidence from 8 countries on how vulnerable households use migration to manage the risk of rainfall variability and food insecurity. Climate and Development, 6, 1-17.

Warner K, Afifi T, Henry K, Rawe T, Smith C, Sherbinin A. (2012). "Where the Rain Falls": Climate change, food and livelihood security, and migration. Global policy report of the Where the Rain Falls Project. Bonn: UNU and CARE.

Warner, K. (2010). Global environmental change and migration: Governance challenges. Global Environmental Change, 20, 402-413.

Wiegel H, Boas I, Warner J. (2019). A mobilities perspective on migration in the context of environmental change. WIREs Clim Change 10: e610.

Williams, N. E., \& Gray, C. (2020). Spatial and temporal dimensions of weather shocks and migration in Nepal. Population \& Environment, 41(3), 286-305.

Zander, K. K., \& Garnett, S. (2020). Risk and experience drive the importance of natural hazards for peoples' mobility decisions. Climatic Change, 162, 1639-1654. 
Zickgraf, C. (2019). Keeping people in place: Political factors of (im)mobility and climate change. Social Sciences, 8(8), 228.

Zickgraf, C. (2018). Immobility. In R. McLeman \& F. Gemenne (Eds.), Routledge Handbook of Environmental Displacement and Migration (pp. 71-84). Routledge.

Publisher's Note Springer Nature remains neutral with regard to jurisdictional claims in published maps and institutional affiliations. 